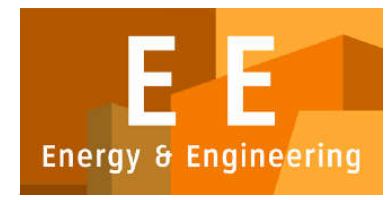

PAPER - OPEN ACCESS

\title{
Product Design Komposter Multifungtional
}

$\begin{array}{ll}\text { Author } & : \text { Ikhsan Siregar, dkk } \\ \text { DOI } & : 10.32734 / \text { ee.v2i3.794 } \\ \text { Electronic ISSN } & : 2654-704 X \\ \text { Print ISSN } & : 2654-7031\end{array}$

Volume 2 Issue 3 - 2019 TALENTA Conference Series: Energy \& Engineering (EE)

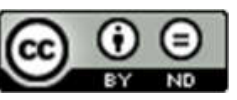

This work is licensed under a Creative Commons Attribution-NoDerivatives 4.0 International License.

Published under licence by TALENTA Publisher, Universitas Sumatera Utara

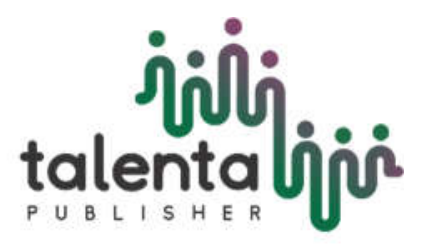




\section{i่ำi TALENTA Conference Series} talentalijis

Available online at https://talentaconfseries.usu.ac.id



\title{
Product Design Komposter Multifungtional
}

\author{
Ikhsan Siregar ${ }^{\mathrm{a}}$, Abdul R Nasution ${ }^{\mathrm{b}}$, Ayu Khairani ${ }^{\mathrm{c}}$, Rinaldi Perdana ${ }^{\mathrm{d}}$,Talitha Almira M \\ a,b,c,d,e Departemen Teknik Industri, Fakultas Teknik, Universitas Sumatera Utara, Medan 20155, Indonesia
}

Jalan Almamater, Kampus USU, Medan, 20155 Indonesia

\begin{abstract}
Abstrak
Desain produk adalah terjemahan kebijaksanaan intelektual, persyaratan pengusaha, atau kebutuhan konsumen, dll. Menjadi produk tertentu. Desainer produk menciptakan konsep dan mengevaluasi ide, membuat ide menjadi kenyataan melalui produk dalam pendekatan yang lebih sistematis. Tujuan dari penelitian ini adalah untuk membuat desain yang lebih inovatif dari produk-produk yang sudah ada sebelumnya pada penolak hama burung bagi petani untuk mengurangi burung hama di sekitar lahan pertanian. Atribut alat berasal dari hasil brainstorming oleh perancang alat. Data ukuran desain diperoleh dari pengamatan langsung dan survei pasar pada produk Penolak Burung yang sudah ada di pasar. Manajemen agribisnis yang berorientasi pasar atau yang disebut agribisnis modern harus diintegrasikan dari hulu ke hilir yang dikoordinasikan dan disatukan menjadi satu organisasi bisnis yang solid dari semua lapisan yang relevan (petani, pengusaha, peneliti ahli, lembaga keuangan, lembaga penelitian dan pemerintah ) agar nilai tambah pertanian dapat dinikmati secara proporsional oleh masing-masing pelaku bisnis Oleh karena itu diperlukan inovasi inovasi tentang teknologi hijau terutama untuk siswa sehingga semua sektor dapat terpenuhi dan dengan desain desain yang diberikan oleh siswa akan dapat menjadi solusi baru untuk masalah yang akan datang.
\end{abstract}

Kata kunci: Komposter, Brainstorming, Desain Produk, sampah organik rumah tangga, pengomposan,

\begin{abstract}
Product design is the translation of intellectual wisdom, requirements of the entrepreneurs, or needs of the consumers, etc. into a specific product. Product designers create concepts and evaluate ideas, making ideas come true through products in a more systematic approach. The purpose of this study is to create a more innovative design of preexisting products on bird pest repellents for farmers to reduce pest birds around farmland. Tool attributes are derived fromresults brainstorming by tool designers. The design size data is obtained from direct observation and survey marketon Bird's Repellent products already on the market. The management of market-oriented agribusinesses or so-called modern agribusiness should be integrated from upstream to downstream that is coordinated and united into a single solid business organization of all relevant layers (farmers, entrepreneurs, expert researchers, finance institutions, research institutions and government) for the added value of agriculture can be enjoyed proportionally by each businessperson therefore it is needed innovation innovation about green technologi especially for students so that all sectors can be fulfilled and with the design of the design given by the students would be able to be a new solution for the problems that will come.
\end{abstract}

Keywords: Komposter, Brainstorming, Product Design, household organic waste, composting

(C) 2019 The Authors. Published by TALENTA Publisher Universitas Sumatera Utara

Selection and peer-review under responsibility of The 3nd National Conference on Industrial Engineering (NCIE)

2019

p-ISSN: 2654-7031, e-ISSN: 2654-704X, DOI: 10.32734/ee.v2i3.794 


\section{Pendahuluan}

Desain produk adalah terjemahan kebijaksanaan intelektual, persyaratan pengusaha, atau kebutuhan konsumen, dll. Menjadi produk tertentu. Desainer produk membuat konsep dan mengevaluasi ide, membuat ide menjadi kenyataan melalui produk dalam pendekatan yang lebih sistematis.[1] Dengan kata lain, desain produk adalah langkah lengkap yang bisa dilakukan untuk mendapatkan desain alat yang diinginkan. Implementasi kebijakan pengelolaan limbah yang secara konvensional menyebabkan peningkatan jumlah sarana dan prasarana, terutama landfill akhirnya semakin sulit mendapatkan lahan yang terbatas. Masalah tanah menjadi masalah yang sangat kompleks karena selain lebih sulit mencari tanah, juga mengandung konflik sosial karena resistensi masyarakat terhadap keberadaan TPA, minimisasi. [2]

Pengelolaan limbah dengan prinsip 3R sudah ditetapkan dalam Strategi Nasional dalam Peraturan Menteri Pekerjaan Umum No. 21 / PRT / M / 2006. Prinsip pertama adalah mengurangi limbah timbulan pada sumber (mengurangi), menggunakan kembali bahan / bahan agar tidak menjadi limbah (reuse), dan mendaur ulang material yang tidak berguna menjadi material lain yang lebih berguna (recycle).[3] Beberapa negara maju telah menerapkan prinsip 3R dalam pengelolaan sampah dapat mengurangi jumlah sampah dan bahkan mengurangi jumlah pembuangan sampah. Di Amerika Serikat pada tahun 1999, daur ulang dan pengomposan mengurangi 64 juta ton limbah yang seharusnya dikirim ke TPA dan jumlahnya TPA berkurang dari 8000 lokasi pada tahun 1998 menjadi 1858 lokasi pada tahun 2001 dengan kapasitas yang relatif sama (Soma, 2010). Sementara di indonesia, menurut laporan Agenda 21 Indonesia: Strategy National For Sustainable Development, 1998 diperkirakan peluang daur ulang adalah sampah (anorganik) mencapai 15 - 25\% dan forcomposting 30 - 40\%. Selain itu, prinsip implementasi 3R dalam pengelolaan limbah juga dapat memberikan manfaat ekonomi kepada masyarakat, salahnya adalah satusatunya adalah melalui bisnis pengomposan. Mereka harus pergi ke sekolah sehingga bagi keluarga miskin mereka tidak dapat mempekerjakan orang lain untuk membantu pekerjaan mereka.

\section{Metodologi Penelitian}

Penelitian dilakukan melalui tiga tahap, yaitu tahap karakteristik sampah organik rumah tangga, tahap pengomposan sampah rumah tangga organik, dan tahap analisis pupuk organik. Langkah pertama dalam desain produk adalah brainstorming. Metode curah pendapat terkenal untuk menghasilkan ide. Ada delapan langkah curah pendapat: membentuk kelompok dan memilih pemimpin kelompok, menginformasikan aturan curah pendapat, pemimpin kelompok menyatakan masalah awal, setiap anggota kelompok memikirkan ide dalam 30 menit, kemudian menulis dan memberikan pendapat tentang ide yang dihasilkan, dan yang terakhir mengumpulkan semua makalah sebagai hasil evaluasi dari brainstorming.

Teknik pengambilan sampel yang akan digunakan adalah purposive sampling karena populasi yang akan dijadikan sampel adalah petani padi. Setelah menentukan jumlah sampel, kuesioner terbuka, kuesioner tertutup, dan kuesioner AHP disiapkan.[4] Semua jenis kuesioner digunakan untuk menentukan apa yang diharapkan petani dari desain alat yang dilakukan. Dengan semua jawaban kuesioner, maka diuji validitas dan reliabilitas jawaban tentang desain perangkat Penolak Burung. Selanjutnya untuk menentukan karakteristik produk digunakan metode QFD. QFD adalah metode untuk meningkatkan kualitas produk atau layanan untuk memahami apa yang dibutuhkan pelanggan dan menghubungkannya dengan ketentuan teknis untuk menghasilkan produk atau layanan di setiap langkah proses pembuatan produk atau layanan.[5] Untuk menemukan solusi untuk masalah apa pun dari membuat produk, langkah-langkah yang menghasilkan alternatif, mengevaluasi, dan meningkatkan detail. Dari semua langkah ini, dapat disimpulkan bahwa produk dapat dibuat dengan atribut dan biaya yang tepat.

\section{Hasil dan Pembahasan}

Permasalahan yang terdapat komposter adalah bentuk kutub, material tiang, warna pahat, bahan balingbaling, diameter baling-baling, jumlah tuas, tinggi alat, fungsi bantu, penggerak, dan diameter tiang pancang. 


\subsection{Tujuan \& Fungsi Klasifikasi, Menentukan Kebutuhan}

Untuk menemukan solusi dari masalah ini, ada 3 langkah sehingga masalah akan dibagi menjadi submasalah, yaitu klasifikasi tujuan \& fungsi, dan penentuan kebutuhan. Kesimpulan dari 3 langkah dalam desain produk pennyebar pupuk adalah:

1. Desain tujuan domain dari produk Penolak Burung meliputi:
a. Volume Tong
b. Bahan pengungkit
c. Jenis-jenis Pipa
d. Komposter warna
e. Faucet Komposter
f. Konektor Pipa
g. Bahan Samping Samping Tong
h. Wadah Hasil Komposter
i. Pengaduk
j. Bahan Penutup Komposter

Bagan Tree Objek dapat dilihat pada Gambar 1. di bawah.

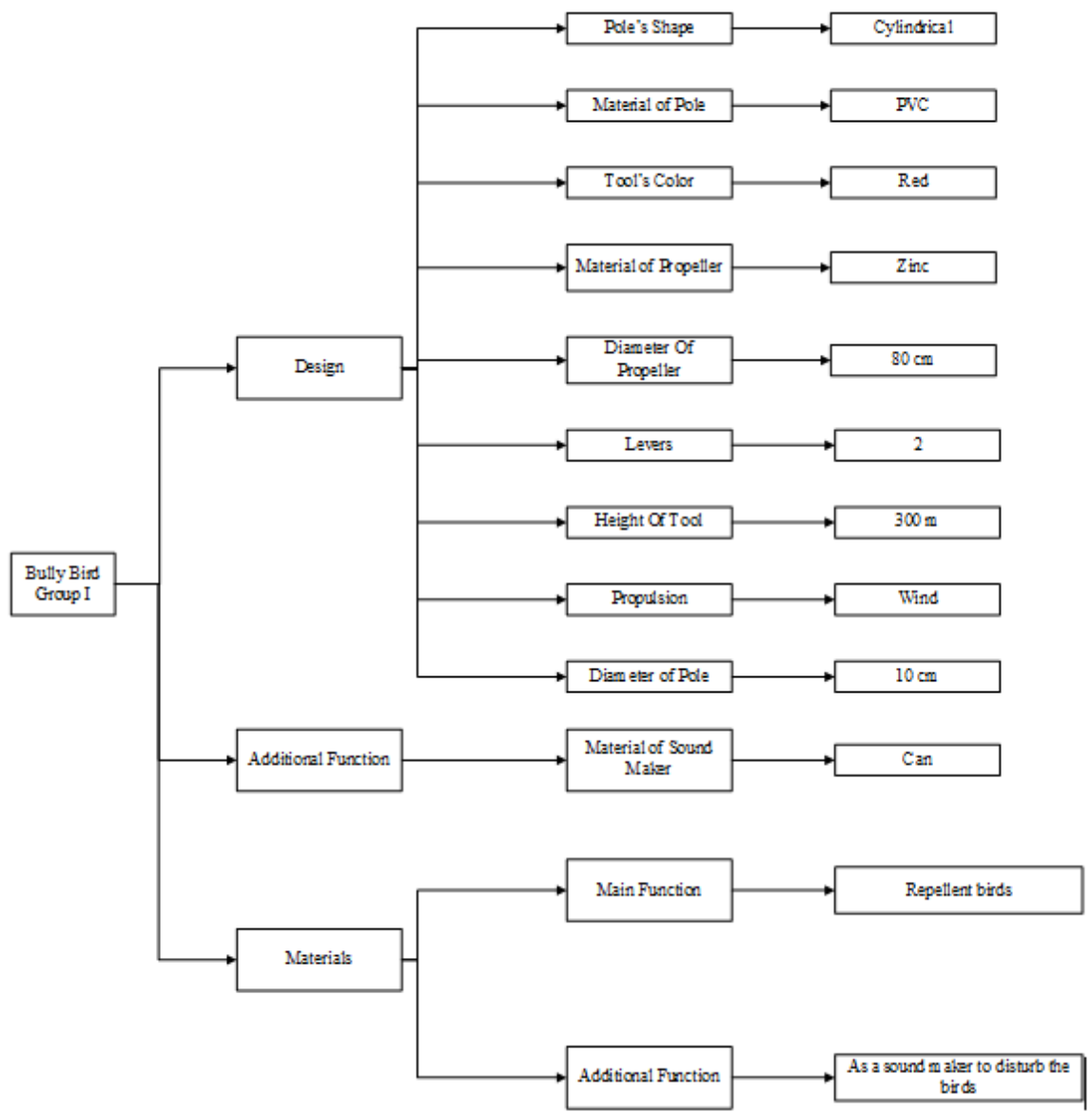

Gambar 1. Diagram Pohon Tujuan

2. Menentukan fungsi

Menentukan fungsi adalah menentukan fungsi-fungsi penting yang diperlukan dan batasan sistem dari desain baru. Fungsi-fungsi penting tersebut adalah:

a. Sub fungsi utama 


\section{b. Sub fungsi tambahan}

3. Menentukan Kebutuhan

Berdasarkan hasil yang diperoleh dari kebutuhan yang ditentukan, Wish> Demand berarti desain produk dasar kepatuhan alat Penolak Burung dengan pelanggan yang diinginkan di pasar. Jadi, sub masalah yang menghasilkan tiga langkah ini adalah:

a. Produk memiliki desain yang nyaman dan ergonomis

b. Produk memiliki masa pakai / daya tahan yang lebih lama

\subsection{Sub Masalah}

Pada bagian ini, sub masalah dari spesifikasi produk alat Penolak Burung akan menemukan sub solusi dengan langkah-langkah desain Nigel Cross, menentukan karakteristik produk. komposter dapat dilihat pada Gambar 2 ini. di bawah.

\begin{tabular}{|c|}
\hline $\begin{array}{l}\text { Degree of Relationship: } \\
\mathrm{V}=\text { Strong Relationship: } 4 \\
\mathrm{v}=\text { Medium Relationship: } 3 \\
\mathrm{x}=\text { Weak Relationship: } 2 \\
\mathrm{X}=\text { No Relations hip; } 1\end{array}$ \\
\hline Vdume Toung $30 \mathrm{~kg}$ \\
\hline Leveage material \\
\hline Types of Pipes 3.4 \\
\hline Color Compester is green \\
\hline Composter fuscess \\
\hline Pipe Connedor \\
\hline Side Coner Materal Tag \\
\hline Combiners of Composter Results \\
\hline Miver \\
\hline Composter Cover Material \\
\hline Degree of Difficulty \\
\hline Degree of Importance \\
\hline CostEstimation \\
\hline $\begin{array}{l}\text { Degree of Difficulty : } \\
1=\text { Easy } \\
3=\text { Medium } \\
5=\text { Hard } \\
7=\text { Harder } \\
9=\text { Hardest }\end{array}$ \\
\hline
\end{tabular}

\begin{tabular}{|l|l|l|l|l|l|l|l|l|l|l|l|}
\hline \\
20
\end{tabular}

Gambar 2. Pengembangan Fungsi Kualitas Grup Alat Penolak Burung



$1-15=$ Cheap $\quad 1-15$ = Less Important

$31-45=$ Expensive $\quad 31-45=$ Very Important 
1. Atribut komposter berdasarkan hasil kuesioner sesuai keinginan pelanggan adalah:

1. 1 Volume Tong: $30 \mathrm{~kg}$

2. Bahan pengungkit: Irpn

3. Jenis Pipa: $3 / 4$

4. Komposter Warna: Hijau

5. Faucet Komposter: Mug

6. Konektor Pipa: T ans L

7. Bahan Samping Samping Tong: al

8. Wadah Hasil Komposter: pipa

9. Mixer: al

10. Bahan Penutup Komposter: tong

2. Perbandingan produk Bully Bird dengan pesaing untuk atribut yang sama berdasarkan persepsi pelanggan adalah sebagai berikut:

a. Untuk bentuk Pole: Produk Grup I, pesaing 1, dan pesaing 2 lebih unggul daripada produk pesaing 3.

b. Untuk material tiang: semua produk sama-sama unggul.

c. Untuk warna alat: semua produk sama-sama unggul.

d. Untuk bahan baling-baling: produk Grup I dan produk pesaing 2 lebih unggul daripada produk pesaing 1 dan produk pesaing 3 .

e. Untuk diameter baling-baling: semua produk sama-sama unggul.

f. Untuk banyak pengungkit: semua produk sama-sama unggul.

g. Untuk ketinggian alat: produk grup I dan pesaing 1 lebih unggul daripada produk pesaing 2 dan 3.

h. Untuk penggerak: 2 produk pesaing lebih unggul dari produk lainnya.

i. Untuk diameter tiang pancang: semua produk sama-sama unggul.

j. Untuk bahan fungsional tambahan: semua produk sama-sama unggul.

3. Kesulitan: semua karakteristik teknis cukup mudah.

4. Tingkat Kepentingan: semua karakteristik teknis penting kecuali untuk durasi perakitan dan panjang pengukuran cukup penting.

5. Biaya Perkiraan: semua karakteristik teknis murah kecuali komposisi produk.

\subsection{Sub Solusi}

Sub solusi berasal dari penyelesaian setiap masalah yang terjadi, termasuk dalam memilih atribut untuk Grup komposter, dengan menggunakan langkah-langkah Nigel Cross dengan mempertahankan manfaat dan meningkatkan kualitas produk. 3 langkah akan digunakan untuk menjadikan sub solusi menjadi solusi, seperti menghasilkan, mengevaluasi alternatif, dan meningkatkan detail. Kesimpulan dari ketiga langkah tersebut adalah:

1. Hasilkan Alternatif

Beberapa solusi desain diterapkan sebagai alternatif pilihan dari alat Penolak Burung dan untuk menemukan solusi dengan menggunakan Bagan Morfologi. Bagan morfologi disajikan dalam bentuk matriks 10 x 3 di mana 10 adalah fungsi yang harus disertai dan 3 adalah alternatif yang mungkin diterapkan. Kombinasi solusi dari desain produk alat Penolak Burung dapat dilihat pada Tabel 3.1 ini. di bawah.

2. Evaluasi Alternatif

Mengevaluasi alternatif adalah membandingkan nilai utilitas dari desain produk alternatif atau digunakan sebagai dasar kinerja atau dasar pembobotan sengaja. Metode ini adalah Tujuan Tertimbang. Untuk melakukan itu, pertama buat daftar tujuan desain produk, kemudian tentukan peringkat semua alternatif dengan Pair Wise Comparison dan AHP Scale. Hasil nilai bobot relatif dari setiap atribut ke atribut lain dapat dilihat pada Gambar 3 ini. di bawah. 


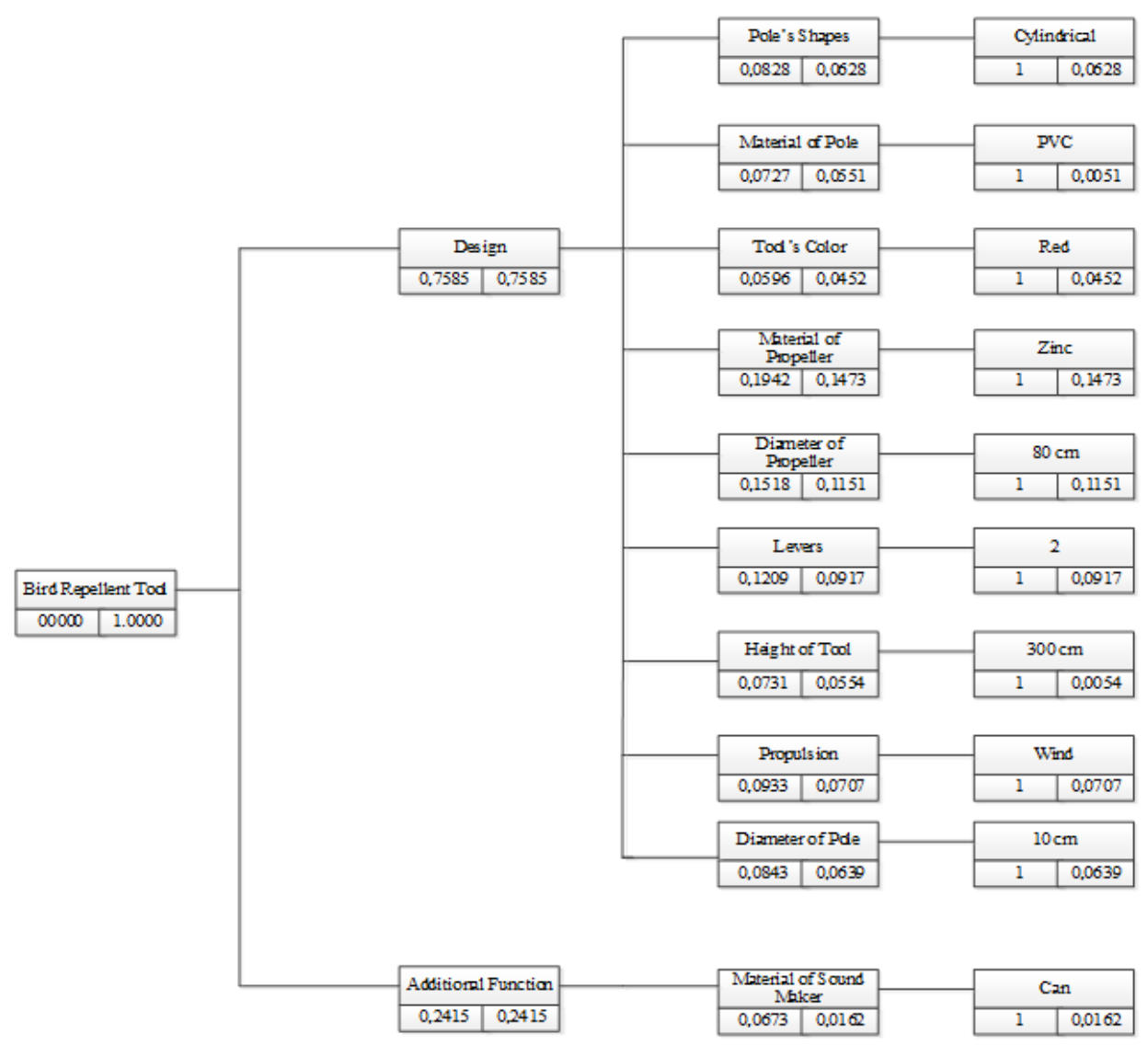

Gambar 3. Nilai Bobot Relatif dari Setiap Atribut ke Atribut lain

Setelah itu, tentukan parameter kinerja dari masing-masing atribut. Parameter kinerja dapat dilihat pada Tabel 1 ini. di bawah.

Table 3.2. Parameter of Performance from Each Attributes

\begin{tabular}{ccccccc}
\hline Characteristics & Parameter & $\mathbf{5}$ & $\mathbf{4}$ & $\mathbf{3}$ & $\mathbf{2}$ & $\mathbf{1}$ \\
\hline Pillar Form & Quality & Best & Good & Normal & Bad & Worst \\
Material pole & Quality & Best & Good & Normal & Bad & Worst \\
Color tool & Quality & Best & Good & Normal & Bad & Worst \\
Material propeller & Quality & Best & Good & Normal & Bad & Worst \\
diameter propeller & Size & 80 & 85 & 86 & 90 & 95 \\
Many levers & Quantity & 2 & 3 & 4 & 5 & 6 \\
Tool height & Size & 300 & 250 & 200 & 150 & 100 \\
Drivers & Quality & Best & Good & Normal & Bad & Worst \\
Diameter of pole & Size & 20 & 15 & 10 & 8 & 5 \\
Additional functional materials & Quality & Best & Good & Normal & Bad & Worst \\
\hline
\end{tabular}

Selanjutnya, hitung dan bandingkan nilai kepentingan relatif dari setiap atribut untuk setiap alternatif. Nilai Penting Berat Alternatif.

Hasil dari setiap pembobotan untuk setiap alternatif adalah:

Alternatif 1: 4.6606

Alternatif 2: 3.8471

Alternatif 3: 3,5153 
Jadi, alternatif yang dipilih adalah alternatif dengan bobot tertinggi, yaitu alternatif 2 dengan nilai total 4.6606.

\subsection{Solusi}

Rekayasa Nilai adalah langkah terakhir dari proses desain yang digunakan untuk meningkatkan nilai produk bagi konsumen dan mengurangi biaya yang harus dibayar oleh produsen. Biaya pembuatan produk Alat Penolak Burung Group I adalah Rp 450.000,00

\section{Kesimpulan}

Kesimpulan yang bisa diambil dari alat komposter desain produk adalah:

1. Komposter yang akan dirancang memiliki bentuk Tiang silinder, PVC, bahan alumunium ; alat hijau, bahan baling-baling adalah seng, diameter baling-baling $80 \mathrm{~cm}$, diameter pipa $3 / 4 \mathrm{~cm}$.

2. Untuk atribut perangkat komposter dapat dibagi menjadi 2 bagian. Atribut utama komposter adalah desain dan fungsionalitas tambahan. Atribut desain dibagi menjadi atribut sekunder yaitu bentuk tiang, material tiang, warna alat, bahan baling-baling, diameter baling-baling, beberapa tuas, tinggi alat, alat propulsi, dan diameter tiang. Atribut fungsi tambahan adalah bahan fungsional tambahan.

3. Untuk QFD ditemukan bahwa semua karakteristik teknik mudah dilakukan.

4. Berdasarkan langkah-langkah rekayasa nilai, dari semua alternatif, ada alternatif terbaik dengan total biaya Rp 450.000,00.

\section{Referensi}

[1] Ginting, Rosnani. 2013. Perancangan Produk. Yogyakarta: Graha Ilmu

[2] Modjoakmint.2012.Rancang Komposter Rumah Sederhana Sistem Mekanik Elektrik. Gorontalo : Universitas Negeri Gorontalo

[3] Kemenperin. 2018. Gambaran Sekilas Industri Karet

[4] Sinulingga. Sukaria. 2008. Pengantar Teknik Industri. Yogyakarta: Graha Ilmu

[5] Hidayatno M, dkk. 2009. Analisis Keberlanjutan Kakao Rakyat Di Perbatasan Pulau Sebatik, Kabupaten Nunukan, Provinsi Kalimantan Timur. Jurnal Agro Ekonomi

[6] Nahar. Julita. 2016. Penerapan Metode Multidimensional Scaling dalam Pemetaan Sarana Kesehatan di Jawa Barat. Jatinangor: Universitas Padjajaran. 